\title{
Carbonation of Circulating Fluidized Bed Combustion Fly Ash with Hybrid Reaction
}

\author{
Ki Gang Lee ${ }^{\dagger}$ and Soon Jong Bae \\ Department of Advanced Material Engineering, Kyonggi University, Suwon 16227, Korea \\ (Received January 15, 2018; Revised February 14, 2018; Accepted February 23, 2018)
}

\begin{abstract}
This paper investigates the reaction rate of $\mathrm{CO}_{2}$ storing carbonation hybrid reaction by comparing the behavior of carbonation between $\mathrm{Ca}(\mathrm{OH})_{2}$ and fly ash with that of CFBC (Circulating Fluidized Bed Combustion) containing plenty of Free-CaO. Because fly ash with CFBC contains a lot of unreacted $\mathrm{CaO}$, it cannot be used as a raw material for concrete admixtures and its usages are limited. To reuse such material, we stabilized unreacted $\mathrm{CaO}$ by carbonation and investigated the carbonation rate. We used a $\mathrm{pH}$ meter and a thermometer to check the rate of the carbonization. Also, we set the contents of fly ash with $\mathrm{CFBC}, \mathrm{Ca}(\mathrm{OH})_{2}$, flow and fluid of $\mathrm{CO}_{2}$, respectively, to $100 \mathrm{~g}, 50 \mathrm{~g}, 100 \sim 1000 \mathrm{cc} / \mathrm{min}$ and $400 \mathrm{~g}$ based on the content of Free-CaO. We used carbonated water instead of water, and added an alkaline activator to promote the carbonation rate. As a result, the addition of the alkaline activator and carbonated water promoted the rate of carbonation via a hybrid reaction.
\end{abstract}

Key words : Alkaline earth oxides, Powders, Hybrid reaction, Carbonation, CFBC fly ash

\section{Introduction}

$\mathrm{M}$ ethods of generating energy using coal in power plants include the pulverized coal combustion (PCC) method and circulating fluidized bed combustion (CFBC) method. The CFBC method can effectively burn high sulfur and low grade coal, and recently there has been increasing interest in this method as a power generation technology due to the outstanding economic feasibility and environmental impact of the equipment related to the method. ${ }^{1)}$ CFBC has a long bituminous coal combustion duration, which can lead to infurnace desulfurization, and the combustion temperature is low, minimizing the production of NOx and reducing the production of particulate matter. However, since this method leads to in-furnace desulfurization, Ca of approximately $2 \sim 2.5$ times the amount of sulfur in the fuel is necessary. So, a large amount of limestone is added, resulting in significant amounts of unreacted $\mathrm{CaO}$ and anhydrous gypsum in the coal ash. This $\mathrm{SiO}_{2}$ content does not meet the KS standard (KS L 5405); thus, the coal ash cannot be recycled and the entire amount is buried. ${ }^{2}$ Also, Korea is currently ranked $7^{\text {th }}$ in the world (for the year 2015) for greenhouse gas emissions. For greenhouse gas emissions to continue to improve, research on carbon capture and storage (CCS) is actively being pursued in order to fulfill the mandatory reduction requirements according to the Kyoto Protocol. ${ }^{3,4)}$

Therefore, the recycling of fluidized bed coal ash requires

${ }^{\dagger}$ Corresponding author: Ki Gang Lee

E-mail : gglee@kyonggi.ac.kr

Tel : +82-31-249-9762 Fax : +82-31-244-6300 mineral carbonation for the stabilization of unreacted $\mathrm{CaO}$; this area is a part of CCS research.

Domestic research carried out by Byeon et al..$^{5)}$ verified the carbonation process of raw materials through carbonation using steel slag, which is an industrial by-product; Ahn et $a l .{ }^{6)}$ showed the applicability of accelerated carbonation technology using carbon dioxide reduction through wet carbonation of waste concrete powder. Moreover, Lee et al. ${ }^{7,8)}$ conducted research on the carbonation reaction rate and carried out experiments to observe the carbonation behavior using fluidized bed coal ash; they attempted to determine whether carbonation is possible and how much solid is produced. ${ }^{9)}$ Additionally, Ahn et $a l{ }^{10)}$ performed carbonation experimentation by fabricating a suspension using $\mathrm{Ca}(\mathrm{OH})_{2}$ as the main ingredient; its reaction rate was determined, and was found to increase linearly with increases of the solid amount and of the temperature. Lee ${ }^{11,12)}$ used additives to waste cement and investigated their impact on the carbonation reaction.

However, research on the carbonation behavior and recycling of fluidized bed coal ash is lacking and, especially, carbonation research on large amounts of fluidized bed coal ash does not yet exist, severely restricting the recycling of fluidized bed coal ash.

Therefore, in this study, to investigate various ways of recycling concrete admixtures, a large amount of fluidized bed coal ash was carbonated and converted to an environmentally and chemically stable material. A preceding study ${ }^{8)}$ used the dissolution reaction of $\mathrm{Ca}^{2+}$ ions produced by the hydration of the $\mathrm{CaO}$ component, which is a rate limiting reaction of the carbonation reaction, and determined the carbonation behavior according to the solid content. 
Experimentation using the dissolution reaction of $\mathrm{CO}_{2}$ to an aqueous solution state, which is another rate limiting reaction in the carbonation process, was performed to compare the carbonation behaviors of unreacted $\mathrm{CaO}$, which is significantly included in the fluidized bed coal ash and $\mathrm{Ca}(\mathrm{OH})_{2}$. An alkali additive was used to investigate the hybrid carbonation mechanism of fluidized bed coal ash through the carbonation reaction rate and temperature.

\section{Experimental Procedure}

\subsection{Carbonation According to the $\mathrm{CO}_{2}$ Flow Rate}

Experiments were carried out to examine the carbonation behavior when the $\mathrm{CO}_{2}$ flow rate was increased to increase the reaction surface areas of $\mathrm{CO}_{2}$ and water. The precipitated calcium carbonate fabrication method of injecting $\mathrm{CO}_{2}$ gas (99\% purity) into the suspension prepared by mixing water and fluidized bed coal ash containing high amounts of $\mathrm{CaO}$, which is the main component of carbon storage, was employed at room temperature. In a plastic beaker of 2000 $\mathrm{ml}$ container volume, the fluidized bed coal ash and water mixed suspension was injected with $\mathrm{CO}_{2}$ to induce carbonation. A magnetic stirrer was used to stir the suspension. After determining that the solid-liquid ratio indicated sufficient stirring of the $\mathrm{CO}_{2}$, experimentation was conducted to determine the reaction rate of the conversion of the $\mathrm{CaO}$ component integrated with $\mathrm{CO}_{2}$ to $\mathrm{CaCO}_{2}$ crystalline phase. In order to identify the carbonation reaction behavior of the fluidized bed coal ash, a suspension was prepared with $\mathrm{Ca}(\mathrm{OH})_{2}$ as the primary ingredient, so that only the $\mathrm{CaO}$ component, and not other components among the ingredients, was converted to $\mathrm{CaCO}_{2}$ crystalline phase; the experiment was conducted by increasing the $\mathrm{CO}_{2}$ flow rate. The carbonation experiment used conditions of $50 \mathrm{~g} \mathrm{Ca}(\mathrm{OH})_{2}$ mass, solid-liquid ratio of $1: 3$, and 5 stage $\mathrm{CO}_{2}$ flow rate between $100 \mathrm{cc} / \mathrm{min} \sim 1000 \mathrm{cc} / \mathrm{min}$. After the carbonation reaction, a $\mathrm{pH}$ meter ( $\mathrm{pH}-230 \mathrm{SD}$, Lutron, Taiwan) was used to measure the $\mathrm{pH}$ change at 2 second intervals and a thermometer (MTM-380SD, Lutron, Taiwan) was used to measure the temperature change in 2 minute intervals to determine the temperature increase due to the exothermic reaction.

\subsection{Carbonation using Carbonated Water}

For the experiment conducted to determine that the $\mathrm{CO}_{2}$ dissolution rate is a rate limiting reaction, a $\mathrm{Ca}(\mathrm{OH})_{2}$ suspension was prepared. Before suspension preparation, $\mathrm{CO}_{2}$ was injected in advance into the fabricated carbonated water; then, the ingredients were added to carry out the carbonation reaction and examine the effect of the rate limiting $\mathrm{CO}_{2}$ reaction. For the experiment conditions, the time dura- tion of $\mathrm{CO}_{2}$ early injection was set to 2 and $3 \mathrm{~h}$, while the solid amount was $50 \mathrm{~g}$, solid-liquid ratio was $1: 3$, and the $\mathrm{CO}_{2}$ flow rate was set to the optimal condition of $700 \mathrm{cc} / \mathrm{min}$ obtained in the above experiment for the carbonation reaction. In order to determine the carbonation reaction rate, the $\mathrm{pH}$ meter was used to identify the neutralization reaction of the $\mathrm{OH}^{-}$ions produced during the hydration of $\mathrm{CaO}$. The $\mathrm{pH}$ meter and thermometer were used to obtain the data for reaction rate determination.

\subsection{Carbonation using Alkali Additives}

Alkali additives were used when fabricating the suspension, and carbonation was conducted to investigate the effect of the $\mathrm{CO}_{2}$ rate limiting reaction, with its dissolution of alkali components $\left(\mathrm{Na}^{+}, \mathrm{Ca}^{2+}\right.$, etc.), on the carbonation reaction rate of the fluidized bed fly ash. The fluidized bed coal ash (Y domestic power plant) used in the experiment had the chemical composition shown in Table 1, where the $\mathrm{CaO}$ and $\mathrm{S}$ components were $38.41 \%$ and $10.15 \%$, respectively, showing that there were significant amounts of unreacted $\mathrm{CaO}$ and gypsum. The fluidized bed coal ash was the same as that used in the experiment conducted by Lee, ${ }^{8)}$ in which the coal ash contained approximately $22 \%$ of unreacted $\mathrm{CaO}$. For the experiment conditions, 3 types of alkali additives, at $2 \mathrm{wt} \%$ each, were used: $\mathrm{NaOH}, \mathrm{Na}_{2} \mathrm{CO}_{3}$, and $\mathrm{NaHCO}_{3}$. A solid amount of $100 \mathrm{~g}$ and solid-liquid ratio of $1: 4$ were used for the carbonation reaction. In order to determine the carbonation reaction rate, the $\mathrm{pH}$ meter was used to identify the neutralization reaction of the $\mathrm{OH}^{-}$ions produced during the hydration of $\mathrm{CaO}$. The $\mathrm{pH}$ meter and thermometer were used to obtain the data for reaction rate determination.

\section{Results and Discussion}

Unreacted $\mathrm{CaO}$ existing within the fluidized bed coal ash hydrates to become solid $\mathrm{Ca}(\mathrm{OH})_{2}$ (Eq. (1) in Table 2 and Reaction (1) in Fig. 1) and ionizes to $\mathrm{Ca}^{++}$and $\mathrm{OH}^{-}$by dissociation (Reaction (2) in Table 2), resulting in the provision of $\mathrm{Ca}^{++}$to the solution and simultaneously increasing the solution $\mathrm{pH}$ due to the $\mathrm{OH}^{-}$ions. This reaction is an endothermic reaction and the carbonation reaction becomes the rate limiting reaction. In order to increase the reaction rate by increasing the $\mathrm{Ca}^{++}$solubility, the reaction can be carried out at low temperature and an ion exchange reaction with $\mathrm{Na}^{+}$can be induced. However, the low temperatures that increase the solubility of the $\mathrm{Ca}^{++}$in water lead to increased process costs; thus, it was determined that the ion exchange reaction with $\mathrm{Na}^{+}$was possible.

Another endothermic reaction of the carbonation reaction is Eq. (3) in Table 2 (Reaction (3) in Fig. 1). Low tempera-

Table 1. Chemical Compositions of CFBC Fly Ash(\%)

\begin{tabular}{|c|c|c|c|c|c|c|c|c|c|c|c|c|c|c|}
\hline & ig-Loss & $\mathrm{SiO}_{2}$ & $\mathrm{Al}_{2} \mathrm{O}_{3}$ & $\mathrm{Fe}_{2} \mathrm{O}_{3}$ & $\mathrm{CaO}$ & $\mathrm{MgO}$ & $\mathrm{Na}_{2} \mathrm{O}$ & $\mathrm{K}_{2} \mathrm{O}$ & $\mathrm{TiO}_{2}$ & $\mathrm{P}_{2} \mathrm{O}_{5}$ & $\mathrm{MnO}$ & $\bar{C}$ & $\bar{S}$ & Total \\
\hline FA & 1.05 & 24.73 & 10.33 & 4.95 & 38.42 & 4.54 & 4.03 & 0.84 & 0.51 & 0.13 & 0.00 & 0.32 & 10.15 & 100 \\
\hline
\end{tabular}


Table 2. Carbonation reaction of Fly Ash

\begin{tabular}{lll}
\hline \multicolumn{1}{c}{ Chemical reaction equation } & \multicolumn{1}{c}{$\Delta G^{\mathrm{c}}\left(\mathrm{KJmole}^{-1}\right)$} \\
\hline $\mathrm{CaO}(s)+\mathrm{H}_{2} \mathrm{O}(l) \Rightarrow \mathrm{Ca}(\mathrm{OH})_{2}(s)$ & $-57.83 \mathrm{KJmole}^{-1}$ & $(1)$ \\
$\mathrm{Ca}(\mathrm{OH})_{2}(s)+\mathrm{H}_{2} \mathrm{O}(l) \Rightarrow \mathrm{Ca}^{2+}(a q)+2 \mathrm{OH}^{-}(a q)+\mathrm{H}_{2} \mathrm{O}(l)$ & $30.42 \mathrm{KJmole}^{-1}$ & $(2)$ \\
$\mathrm{CO}_{2}(g)+\mathrm{H}_{2} \mathrm{O}(l) \Rightarrow \mathrm{CO}_{2}(a q)+\mathrm{H}_{2} \mathrm{O}(l)$ & $8.38 \mathrm{KJmole}^{-1}$ & $(4)$ \\
$\mathrm{CO}_{2}(a q)+\mathrm{OH}^{-}(a q) \Rightarrow \mathrm{HCO}_{3}^{-}(a q)$ & $-43.55 \mathrm{KJmole}^{-1}$ & $(5)$ \\
$\mathrm{HCO}_{3}^{-}(a q)+\mathrm{OH}(a q) \Rightarrow \mathrm{H}_{2} \mathrm{O}(l)+\mathrm{CO}_{3}^{2-}(a q)$ & $-20.92 \mathrm{KJmole}^{-1}$ & $(6)$ \\
$\mathrm{Ca}^{2+}(a q)+\mathrm{CO}_{3}^{2-}(a q) \Rightarrow \mathrm{CaCO}_{3}(s)$ & $-47.40 \mathrm{KJmole}^{-1}$ & \\
\hline
\end{tabular}

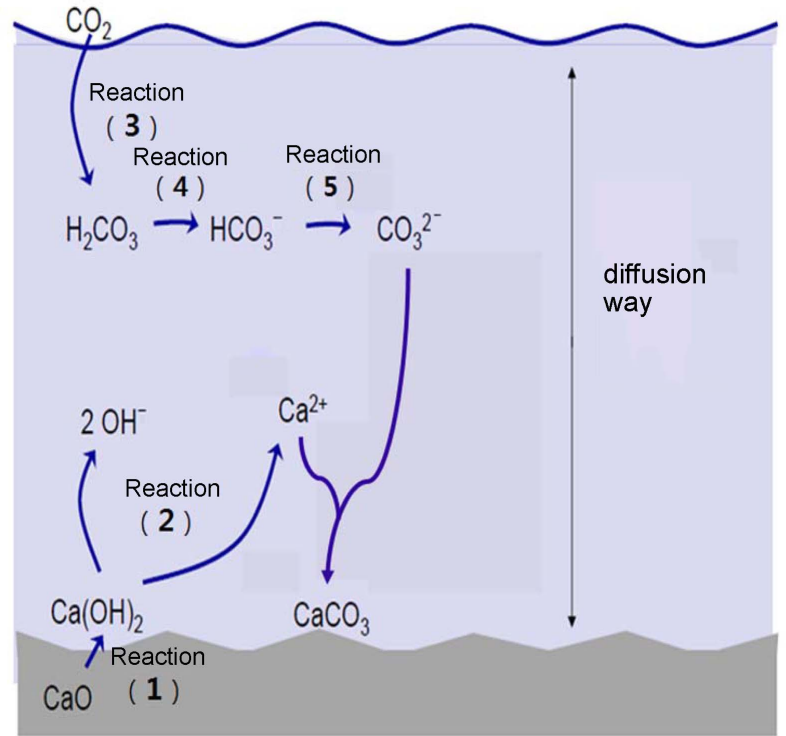

Fig. 1. Schematic process of carbonation in water. ${ }^{8)}$

tures and high $\mathrm{pH}$ environments are advantageous to increase the solubility of $\mathrm{CO}_{2}$; however, low temperatures are costly, and thus it was determined that increasing the $\mathrm{pH}$ through alkali addition was advantageous.

Therefore, the $\mathrm{CO}_{2}$ flow rate was increased to catalyze the carbonation of fluidized bed coal ash, and carbonated water or alkali promoters were used to carry out the carbonation experiments.

\subsection{Carbonation Experiment According to $\mathrm{CO}_{2}$ Flow Rate Variation}

Carbonation experiments were conducted by fabricating suspensions with a solid-liquid ratio of 1 : 3 between $\mathrm{Ca}(\mathrm{OH})_{2}$ and water and with 5 stages for the $\mathrm{CO}_{2}$ flow rate between $100 \sim 1000 \mathrm{cc} / \mathrm{min}$. Fig. 2 shows the $\mathrm{pH}$ data results for the carbonation experiment according to the $\mathrm{CO}_{2}$ flow rate change. Fig. 3 shows the temperature variation graph for the exothermic reaction in the carbonation process. The carbonation results show that the carbonation reaction rate completion time (the time until the $\mathrm{pH}$ becomes neutral, when the $\mathrm{OH}^{-}$ions of the $\mathrm{CaO}$ component are removed and converted to $\mathrm{CaCO}_{3}$ ) decreased as the $\mathrm{CO}_{2}$ flow rate increased. As the $\mathrm{CO}_{2}$ flow rate increased, the reaction surface area of $\mathrm{CO}_{2}$ and water increased, increasing the $\mathrm{CO}_{2}$

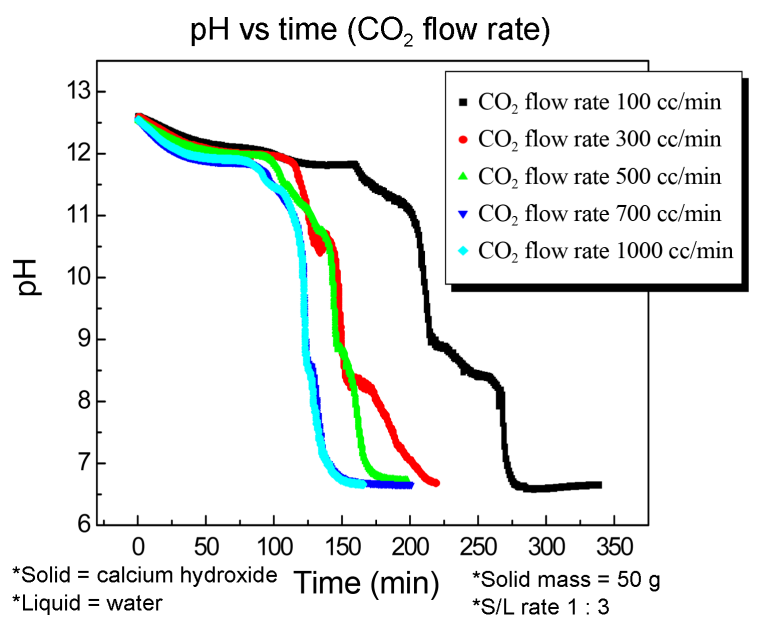

Fig. 2. Variation of $\mathrm{pH}$ of $\mathrm{Ca}(\mathrm{OH})_{2}$ carbonation reaction with flow rate of $\mathrm{CO}_{2}$.

aqueous solution state in the suspension and accelerating Eq. (3) to change $\mathrm{CO}_{2}$ to an ionization state. As the $\mathrm{CO}_{2}$ flow rate increases, the carbonation reaction rate increases but by comparing the values at $700 \mathrm{cc} / \mathrm{min}$ and $1000 \mathrm{cc} / \mathrm{min}$, it was found that there was no further increase after $700 \mathrm{cc} /$ min. It can be deduced that, because there is a limit to the solubility of $\mathrm{CO}_{2}$, a surface area limit existed for the reaction between water and $\mathrm{CO}_{2}$.

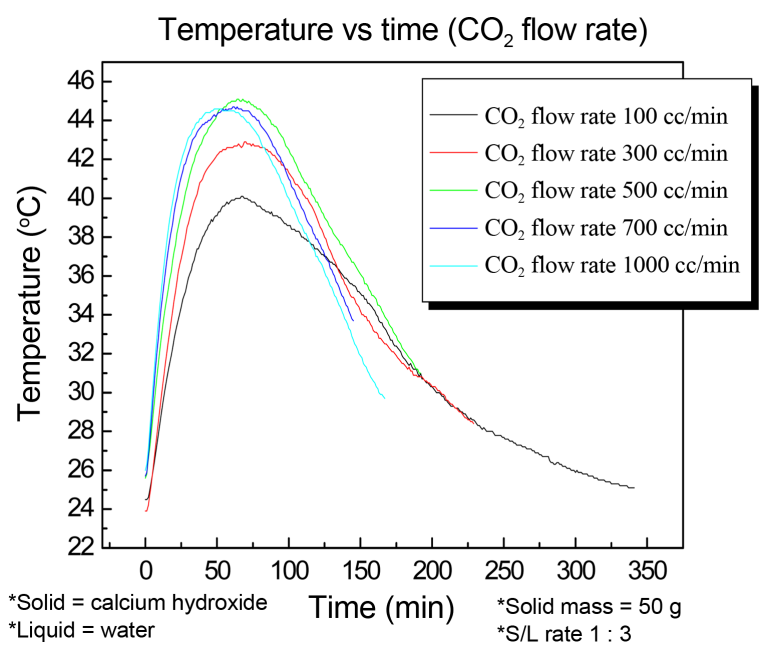

Fig. 3. Temperature variation of $\mathrm{Ca}(\mathrm{OH})_{2}$ carbonation reaction with flow rate of $\mathrm{CO}_{2}$. 
Figure 3 shows that the times until the maximum temperature was reached were essentially the same. This reveals that the exothermic reaction occurred at the same time and the temperature increased as the reaction was made more active through the increase of $\mathrm{CO}_{2}$ flow rate. Also, the temperature did not increase further when the $\mathrm{CO}_{2}$ solubility limit was reached at $700 \mathrm{cc} / \mathrm{min}$. Through this, the carbonation behavior was identified for times when the reaction surface areas of $\mathrm{CO}_{2}$ and water were increased.

\subsection{Effect of Carbonated Water on Carbonation}

Carbonation was carried out for the conditions of $1: 3$ solid-liquid ratio between $\mathrm{Ca}(\mathrm{OH})_{2}$ and water and fixed $\mathrm{CO}_{2}$ flow rate of $700 \mathrm{cc} / \mathrm{min}$. Carbonation was also carried out using carbonated water fabricated by feeding $\mathrm{CO}_{2}$ in advance for 2 and 3 h. Fig. 4 shows the carbonation $\mathrm{pH}$ data for the case of advanced $\mathrm{CO}_{2}$ feeding; Fig. 5 provides a temperature variation graph for the exothermic reaction in the carbonation process.

The $\mathrm{pH}$ data revealed that the reaction rate increased with early $\mathrm{CO}_{2}$ feeding for the carbonated water fabrication case. This increased reaction rate result was thought to be due to the hybrid reaction used in the conversion of the $\mathrm{CO}_{2}$ directly to the aqueous solution state by adding activation energy (Eqs. (4) and (5) of Table 2) to the slurry through an early reaction of water and $\mathrm{CO}_{2}$. Moreover, the lack of difference between the reaction rates for the $2 \mathrm{~h}$ and $3 \mathrm{~h}$ cases was considered to be due to the $\mathrm{CO}_{2}$ solubility limit.

The temperature graph shows that the times until maximum temperature in both Figs. 3 and 5 were almost the same. This reveals that the time that the exothermic reactions take are the same, and the carbonated water fabrication reaction produced a greater activation energy and activated the reaction, resulting in the elevated temperature within the suspension. Additionally, the solubility limit of $\mathrm{CO}_{2}$ is thought to be the cause behind the identical reaction completion times for the $2 \mathrm{~h}$ and $3 \mathrm{~h}$ cases.

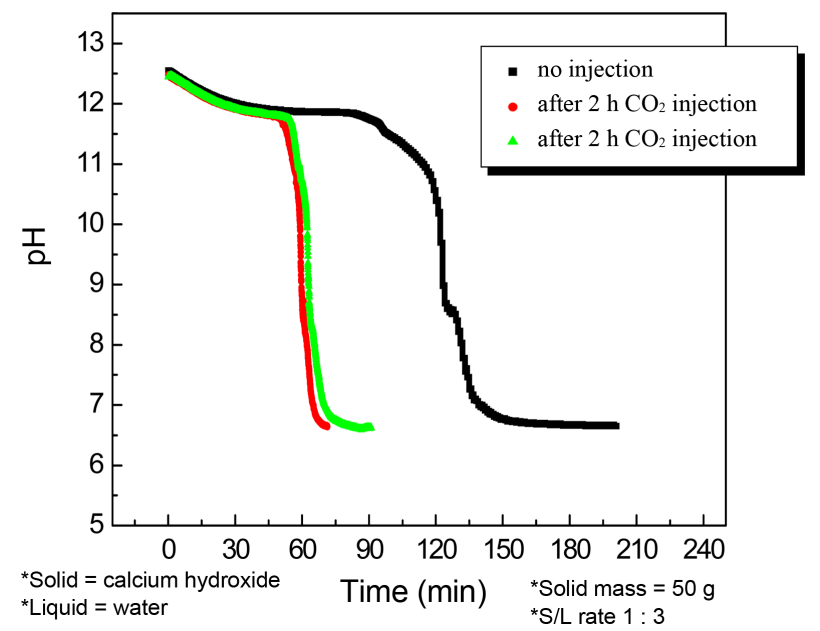

Fig. 4. Variation of $\mathrm{pH}$ of $\mathrm{Ca}(\mathrm{OH})_{2}$ carbonation reaction according to whether or not reaction comes ahead of $\mathrm{CO}_{2}$ injection.

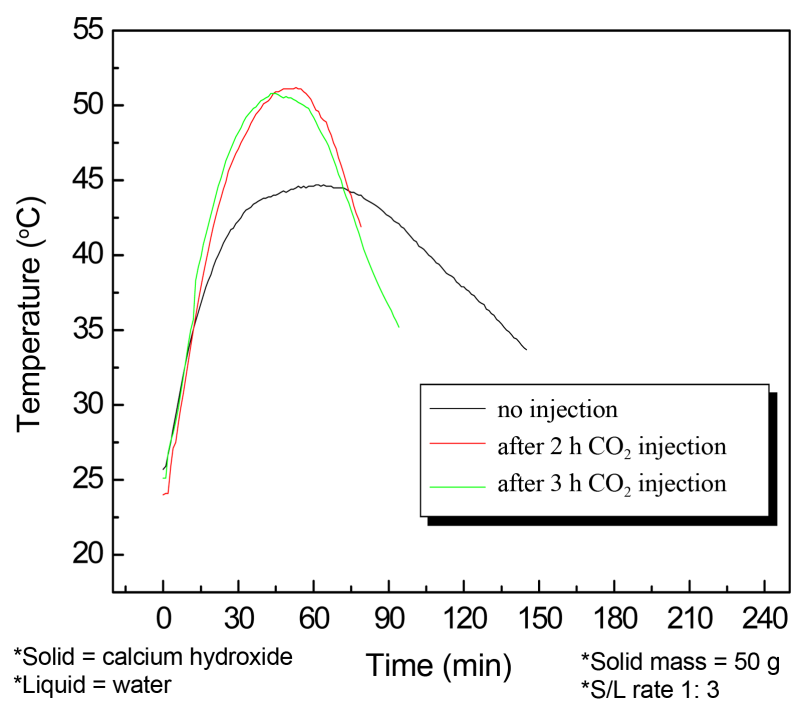

Fig. 5. Temperature variation of $\mathrm{Ca}(\mathrm{OH})_{2}$ carbonation reaction according to whether or not reaction comes ahead of $\mathrm{CO}_{2}$ injection.

\subsection{Effect of Alkali Promoters on Carbonation Reac-} tion

Alkali promoters not only enhance the solubility of $\mathrm{Ca}^{++}$ through ion exchange with $\mathrm{Ca}^{++}$, but can also increase the solubility of $\mathrm{CO}_{2}$. Carbonation occurs through the following reaction for alkali promoters. ${ }^{1)}$

$$
\begin{aligned}
& \mathrm{Na}_{2} \mathrm{CO}_{3}+\mathrm{H}_{2} \mathrm{O} \rightarrow 2 \mathrm{NaOH}+\mathrm{CO}_{2} \\
& \rightarrow \mathrm{NaOH}+\mathrm{NaHCO}_{3} \\
& \mathrm{NaOH}+\mathrm{NaHCO}_{3}+\mathrm{CaO} \rightarrow 2 \mathrm{NaOH}+\mathrm{CaCO}_{3}
\end{aligned}
$$

According to the above equations, $\mathrm{NaOH}, \mathrm{Na}_{2} \mathrm{CO}_{3}$, and $\mathrm{NaHCO}_{3}$ were used as the alkali promoters.

For the suspension, the solid-liquid ratio between the fluidized bed coal ash and water was $1: 4$, the $\mathrm{CO}_{2}$ flow rate was fixed at $700 \mathrm{cc} / \mathrm{min}$, and the alkali activators $\mathrm{NaHCO}_{3}$,

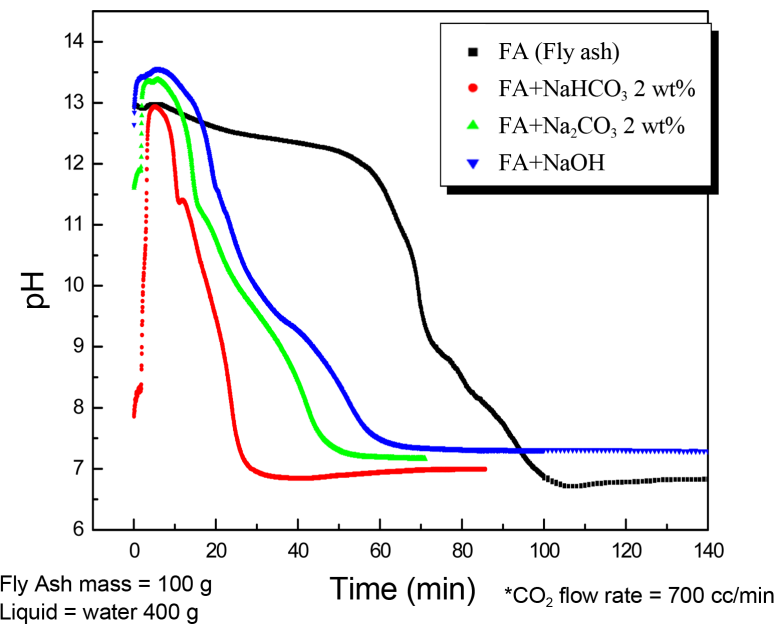

Fig. 6. Variation of $\mathrm{pH}$ of Fly ash carbonation reaction with various alkali compounds. 


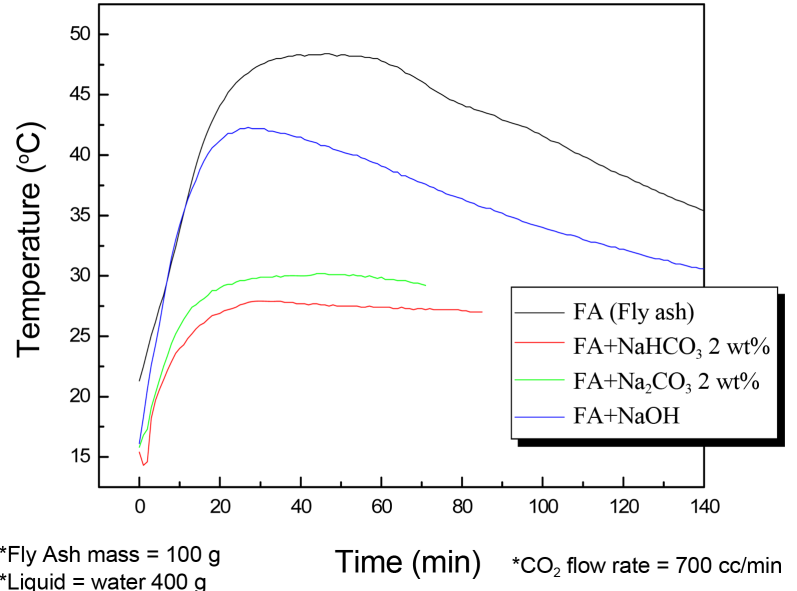

Fig. 7. Temperature variation of Fly ash carbonation reaction with various alkali compounds.

$\mathrm{Na}_{2} \mathrm{CO}_{3}$, and $\mathrm{NaOH}$ were each added at $2 \mathrm{wt} \%$ for carbonation. Fig. 6 shows the $\mathrm{pH}$ data graph for the carbonation experiment results using alkali promoters in the suspension. The hybrid reaction catalyzing the carbonation reaction was observed for the alkali activator added carbonation results.

The alkali ion addition case showed an initial slight increase in $\mathrm{pH}$. The alkali ion addition accelerated the ion exchange to produce more $\mathrm{OH}^{-}$and, as a result, promoted the dissolution of $\mathrm{CO}_{2}$ and accelerated the production of $\mathrm{CO}_{3}{ }^{2-}$. Consequently, the reaction rate was found to increase. Furthermore, when $\mathrm{NaHCO}_{3}$ was added, the reaction rate acceleration reached its highest value. This result was determined to be due to the effect of the $\mathrm{HCO}_{3}{ }^{-}$ions, produced through the dissolution of the additive and acting as seeds, on the reaction rate.

Figure 7 provides a temperature graph for this reaction and, similarly, the exothermic reactions were found to finish at almost the same times. Not only that, the maximum temperature was so low that it was possible to carry out the car-

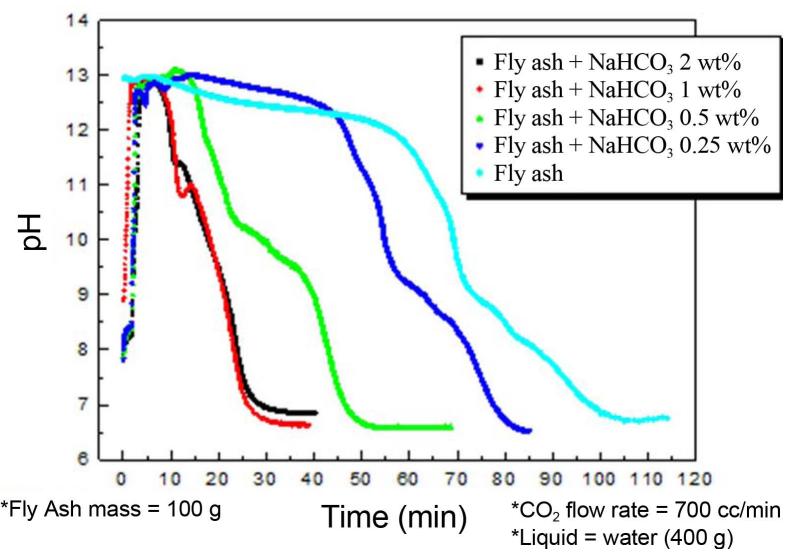

Fig. 8. Variation of $\mathrm{pH}$ of Fly ash carbonation reaction with $\mathrm{NaHCO}_{3}$ alkali compound mass.

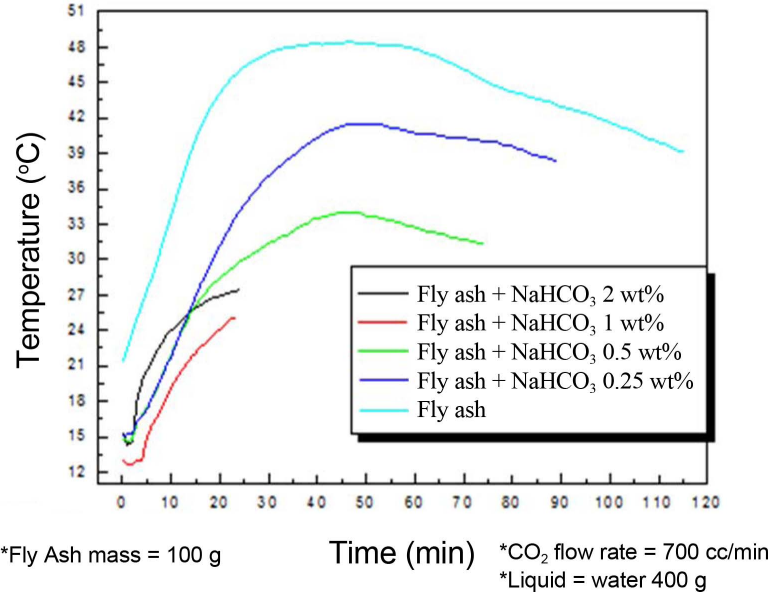

Fig. 9. Temperature variation of Fly ash carbonation reaction with $\mathrm{NaHCO}_{3}$ alkali compound mass.

bonation reaction at an accelerated pace. This result was determined to be due to the additive reducing the reaction indicated by Eq. (4) in Table 2 and decreasing the heat generation.

Figure 8 shows the carbonation reaction according to the $\mathrm{NaHCO}_{3}$ additive amount; this case showed the greatest increase of reaction rate. It was observed that the carbonation reaction was accelerated as the additive amount increased. This result was similarly due to ion exchange facilitated by the additive; the reaction accelerated as the additive amount increased. Also, when more than $1 \mathrm{wt} \%$ was added, the carbonation reaction did not increase further, revealing the existence of a reaction limit. The temperature graph in Fig. 9 shows that the maximum temperature decreased as the reaction became more active; this was determined to be due to the decreased of the reaction indicated in Eq. (4) in Table 2 and to more $\mathrm{HCO}_{3}{ }^{-}$acting as a seed to reduce heat generation.

\section{Conclusions}

$\mathrm{CO}_{2}$ flow rate, carbonated water preparation, and alkali additives were used to carry out carbonation experiments in order to investigate the carbonation reaction behavior of the $\mathrm{CaO}$ component using fluidized bed coal ash and $\mathrm{Ca}(\mathrm{OH})_{2}$. Carbonated water preparation and alkali additives were used to induce reactions other than the main reaction $\left(\mathrm{CO}_{2}\right.$ flow rate) to control the activation energy; the hybrid reaction combining the two reactions was used to control the carbonation reaction rate.

The following 3 experiments were conducted to control, among the carbonation reactions, the conversion reaction from $\mathrm{CO}_{2}$ to an aqueous state.

1. Experiment to investigate the reaction surface areas of $\mathrm{CO}_{2}$ and water

Through the reaction of water and $\mathrm{CO}_{2}$, increasing the 
$\mathrm{CO}_{2}$ flow rate to $100 \sim 1000 \mathrm{cc} / \mathrm{min}$ resulted in an active reaction and saturation solubility was obtained when the $\mathrm{CO}_{2}$ flow rate was $700 \mathrm{cc} / \mathrm{min}$. In the case of the temperature, the times at which the maximum temperature was reached were almost the same, leading to the conclusion that the exothermic reaction occurred at the same time.

2. Carbonation reaction through fabrication of carbonated water by early feeding of $\mathrm{CO}_{2}$

The reaction rate was found to increase when water and $\mathrm{CO}_{2}$ were reacted before the carbonation reaction to create activation energy within the slurry for use in the conversion reaction from $\mathrm{CO}_{2}$ to an aqueous state (Reaction (3)). Through this result, it was determined that the process water of the carbonation reaction can increase the reaction rate.

\section{Carbonation using alkali additive}

When the carbonation reaction was conducted using alkali additives to promote ion exchange, dissolution of $\mathrm{CO}_{2}$ was accelerated to induce the active production of $\mathrm{CO}_{3}{ }^{2-}$ and to catalyze the carbonation reaction via the seed role of $\mathrm{HCO}_{3}^{-}$. Also, in the case of temperature, the rate of Reaction (4) decreased along with heat generation, resulting in decreased temperatures. The $\mathrm{NaHCO}_{3}$ additive showed the greatest acceleration of the carbonation reaction due to the sufficient seed role played by the production of $\mathrm{HCO}_{3}^{-}$ions.

Through this, the carbonation reaction rate of the carbon storage fluidized bed coal ash containing the $\mathrm{CaO}$ component was determined and the $\mathrm{CO}_{2}$ reaction was controlled using the activation energy produced by carbonated water and the alkali additive. As a result, it was possible to predict the reaction rate of the wet carbonation reaction and its behavior. In conclusion, to stabilize unreacted $\mathrm{CaO}$ and allow this material to be recycled for use in various construction fields, $\mathrm{CO}_{2}$ can be stored in the $\mathrm{CaO}$ component in waste produced from thermal power plants.

\section{Acknowledgments}

This work was supported by the Kyonggi University Research Grant 2015.

\section{REFERENCES}

1. W. G. Lee, J. E. Kim, S. H. Jeon, and M. S. Song, "Carbonation of Circulating Fluidized Bed Boiler Fly Ash Using Carbonate Liquids," J. Korean Ceram. Soc., 54 [5] 380-87 (2017).

2. S. H. Lee and G. S. Kim, "Self-Cementitious Hydration of Circulating Fluidized Bed Combustion Fly Ash,” J. Korean Ceram. Soc., 54 [2] 128-39 (2017).

3. N. S. Ahn, J. H. Lee, and Y. H. Lee, "Sulfate Attack According to the Quantity of Composition of Cement and Mineral Admixtures," J. Korea Inst. Build. Constr., 11 [6] 547-56 (2011).

4. K. H. Kim, J. Y. Lim, D. H. Ryu, and S. W. Choi, "The Present Situation of Production and It's Utilization of Electronic arc Furnace Oxidizing Slag in Korea and Other Countries," J. Korea Concr. Inst., 19 [6] 51-7 (2007).

5. T. B. Byeon, J. Y. Lee, D. Y. Kim, H. H. Lee, and H. S. Kim, "Carbonation Treatment Technology of Steel Making Slag," RIST J. R\&D., 19 [1] 32-9 (2005).

6. J. W. Ahn, H. S. Kim, J. S. Cho, G. C. Han, K. S. Han, and H. Kim, "Manufacture of Ordinary Portland Cemnet Clinker Using Cement Paste of the Waste Concrete," J. Korean Ceram. Soc., 40 [8] 804-10 (2003).

7. K. G. Lee, J. S. Kim, Y. T. Kim, and S. K. Kang, "Carbonization of Coal-Fly Ash Containing High CaO Compound," J. Korean Ceram. Soc., 50 [1] 18-24 (2013).

8. K. G. Lee and S. J. Bae, "Carbonization Behavior of Fly Ash with Circulating Fluidized Bed Combustion (CFBC)," J. Korean Ceram. Soc., 52 [2] 154-58 (2015).

9. J. S. Sim, K. G. Lee, Y. T. Kim, and S. K. Kang, "Hydration Characteristics of Coal-Fly Ash Containing High CaO Compound," J. Korean Ceram. Soc., 49 [2] 185-90 (2012).

10. J. W. Ahn, J. W. Park, J. S. Kim, and C. Han, "A Study on Characteristics of Precipitated Calcium Carbonate Prepared by the Nozzle Spotting Method," J. Kor. Chem., 17 [1] 67-72 (2006).

11. H. Y. Jo, J. H. Kim, Y. J. Lee, M. H. Lee, and S. J. Choh, "Evaluation of Factors Affecting Mineral Carbonation of $\mathrm{CO}_{2}$ Using Coal Fly Ash in Aqueous Solutions under Ambient Conditions," Chem. Eng. J., 183 77-87 (2012).

12. H. M. Lee, J. Y. Hwang, J. H. Lee, B. S. Son, and J. H. Oh, "The Effect of Chloride Additives and $\mathrm{pH}$ on Direct Aqueous Carbonation of Cement Paste," J. Mineral. Soc. Korea, 28 [1] 39-49 (2015). 